\title{
Scholarly Publication, Academic Libraries, and the Assumption That These Processes Are Really under Management Control
}

\section{Herbert White}

It has long been assumed that the refereeing process used by scholarly journals served as an effective safeguard against the publication of work that is either inferior or repetitive of earlier publications. However, the tremendous increase in publication volume that cannot be reconciled with the number of scholars undertaking and reporting their research suggests that the process has developed cracks, if indeed it has not broken down completely. Pressures to publish everything "somewhere" not only protect the most significant journals but also channel the remaining articles into lesser journals, which are equally protected directly by the researchers forced to publish in them, even if they are reluctant to do so. This phenomenon also negates publishing on demand or electronic storage and retention as effective alternatives. Libraries are increasingly important to publishers because studies have shown that the nonlibrary purchasing base for scholarly journals continues to erode, while libraries are constantly pressured with regard to what they are supposed to buy. In addition, scholars often play the simultaneous and conflicting roles of author, reviewer, editor, reader, academic credit dispenser, and credit recipient. This paper suggests the need for new and more objective approaches to the "publication situation," rather than merely obeying the dictates of the marketplace and the "credit machine."

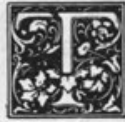

he article makes no attempt at a complete survey of the literature on this topic, a literature with contributions from both librarians and publishers, and one that is growing rapidly. Much of this literature is narrowly self-justifying, and it has been addressed in this paper only as necessary to document its own assessments.

\section{THE PRESUMED VALIDITY OF SCHOLARLY PEER ASSESSMENT OF PUBLICATION WORTHINESS}

Throughout recorded history, scholars, scientists, musicians, and artists have struggled for the freedom to set their own work agendas and to be judged by groups of their own peers rather than by outsiders. They have understood that evaluation either by a political body or by funding patrons might impose a value system of "political correctness," or one that simply rewards what interests and appeals to the patron and sponsor. Examples of this have ranged from the forced recanting of Galileo of what he knew to be true to more recent examples of politically acceptable music, with the determination made through the application of inexplicable and arbi-

Herbert White is a Distinguished Professor in the School of Library and Information Science at Indiana University, Bloomington, Indiana 47405. 
trary standards we still do not understand.

The attitude of scholars has been consistently that they and only they should be the judges of what represents quality work, and that the decision should be made by the evaluation of peers in the scholar's own discipline. It is the scholarly argument that this judgment, and not the opinion of bureaucratic officials, should determine what is worthwhile and should be published.

\section{It is possible that celebrities in}

areas of scholarship and research are required to spend much of their time talking and writing about what they have already done, and therefore have little time to do anything new.

Scholars, who insist on the premise that their own judgment of the work of colleagues is both fair and impartial, implement this process through the mechanism of peer review. This review occurs both in the determination of who should receive support and funding for carrying out his or her research, and in a refereeing process that controls publication in leading journals. From the start, it has been evident that this procedure, while perhaps preferable to any identified alternative, works at best uncertainly. Recently questions have arisen about how well it works at all.

\section{THE ELITISM OF THE PROCESS}

It has been a long time since Derek de Solla Price first noted the existence of the invisible college, an informal network of scholars that bypasses both the rigor and the time constraints of the formal review and communication processes. The invisible college has both supporters and critics, and largely this depends on whether the individual making the judgment sees himself or herself as a member of the invisible college. ${ }^{1}$ There can be little doubt that the process of informal and immediate communication, supported by electronic message systems, works well for those who are already recognized by their peers as legitimate scholars. It does not work nearly so well for the newcomers who have yet to achieve such status. In other words, it recognizes and credits past achievement in preference to the present work presumably being communicated and evaluated. It tends to be a historical rather than an up-to-date evaluative tool. And yet there are countless indications that suggest, for example in the areas of the physical and biological sciences (although a case could be made equally easily for poetry and music), that most of the breakthroughs later seen as significant are made by newcomers, and these contributions are not quickly recognized precisely because they come from individuals from whom such contributions were not expected. It is possible that celebrities in areas of scholarship and research are required to spend much of their time talking and writing about what they have already done, and therefore have little time to do anything new. That was the complaint of the developers of DNA. The invisible college, certainly prominent long before Price named it, works to some extent, but it works unfairly and inefficiently because it judges not the new specific contribution but the reputation that the individual currently holds. To place a contextual setting on an old joke: Where do Nobel Prize recipients publish? Anywhere they like!

The same sort of prejudging bias has been leveled, at least in the United States, against panels that award research funds. In principle, the process is supposed to focus on the proposed project, and not on the qualifications of the investigator that relate to previous work that may be irrelevant to this effort. However, panels are composed of human beings, and human beings frequently prefer to make safe rather than risky decisions. The opportunity for criticizing (with totally clear hindsight) the decision of an award jury, which did not use criteria that led to productive results, is always available. The criticism must be muted when it is noted that the past work of the applicant gave every indication of future success. Giving more 
money to former recipients is a safer decision. And that is why such panels look at citation statistics for earlier work by the same individual-sometimes claiming that past achievement predicts future success.

\section{WHY RESEARCHERS MUST PUBLISH}

There is obviously a connection between funding support and the generation of the scholarly and research publications on which this paper focuses, but that connection is not as direct as one might assume. The purpose of publication is, after all, a twofold one. The first and the most immediately recognized purpose is the communication of findings, sometimes to an eager audience and sometimes to a disinterested one. The former is preferable, but even the latter is acceptable, because the other purpose of scholarly publication is the achievement of academic credit. Unfortunately, as will be discussed below, credit depends less on the quality and more on the quantity of activity in today's academic marketplace. Studies at the University of Pittsburgh indicated that much material that resides in research libraries is never read. ${ }^{2}$ My own earlier studies indicated that for whole categories of disciplines, libraries were the only subscribers to certain journals. These studies suggest a situation in which scholarly publications are read by nobody and are of interest to nobody. ${ }^{3}$ Does that negate their value? To society perhaps, but not necessarily to the author.

The premise of quality control in the evaluation of submissions to scholarly journals is based on the concept of double-blind refereeing-the author does not know who the reviewers are, and the reviewer does not know who the author is. The process might work for the author, but it works ineffectively for the reviewers. To a large extent the same preconceptions that affect the invisible college and the awarding of grants apply here as well. Many scholarly communities are small; specialties of members are well-known to all possible peer reviewers.
While there are still major interdisciplinary journals, the process of journal publication has become narrower and more specialized. Much of this trend developed with the entry of commercial publishers into the arena of publishing scholarly and research journals. Early studies indicated that scholarly journal publishing was a field dominated by the for-profit sector and by professional societies, with the second group largely emphasizing discipline-wide publications fitting the characteristics of the society membership. ${ }^{4}$

\section{THE ECONOMICS OF JOURNAL PUBLISHING}

The development of narrow, specialized journals owes its impetus to many sources, but the economic opportunities were grasped perhaps most directly by Robert Maxwell and his development of new journals for Pergamon Press. Maxwell clearly saw one obvious but rarely discussed difference between monograph and journal publishing. Monographic publication involves a great deal of cash flow investment and risk. Monographs must be contracted, edited, and printed, and a supply must be placed into the warehouse before the first copy can be sold. The publisher has invested in an expensive inventory, and then must play a highly dangerous game. Unsold copies, particularly concerning subjects for which information changes rapidly, have virtually no value. This fact discourages massive speculative print runs. However, it also eliminates the likelihood of huge profits, since successful monographs rapidly go out of print. The publisher has then made what is probably a modest profit, but consequently faces a new and dangerous business decision of whether to reprint. If so, how many copies? Might this decision lead to the additional expense of yet another reprint? Or, might the publisher be burdened with an unsold and useless inventory? It might be better to look for an updated work instead, perhaps through a second or revised edition, or through another author. These are some of the difficult choices facing monograph publishers. 
Journal publishers face far fewer risks. They receive payment for the entire subscription year (and sometimes for multiple years) before making any expenditures. Those funds, even if cautiously invested, produce interest income, in contrast to the interest expenses that monographic publishers face. Print runs are known well in advance, and the publisher has few responsibilities for maintaining back sets, particularly if these are available on microfilm. Unsuccessfully promoted titles can be aborted, sometimes before the first issue is printed, and it may not even be necessary to offer a refund. There is always the potential option of suggesting that the funds already contributed be diverted to other titles offered by the same publisher. That strategy was described in a presentation and subsequently in an article submitted to the scholarly publishing community itself. The members of the community expressed little dispute or disagreement with the conclusions presented. 5

The mechanisms so carefully developed by Maxwell and others depended not on developing and publishing large-circulation, inclusive-topic journals, but rather on promoting highly focused publications. These journals are so specialized that they often have only one or two interested readers in any major university. Publishers can bring out these journals infrequently (quarterly, at the most) and they can charge high subscription rates to university libraries because the targeted reader considers these highly specialized journals to be more important than any other. Consequently it has become nearly impossible for university libraries to refuse to subscribe to key journals aimed at specific scholars and researchers whom the library serves.

The publication process described above thus created a whole series of invisible colleges, i.e., small groups of researchers working in a particular subdiscipline or even subsubdiscipline. Key members of each invisible college are identified and selected to be editors of journals or members of the editorial advisory board. These appointments engender a great deal of prestige but often very little work responsibility. New and junior researchers anxious to join this small and select group feel pressured to write articles for these journals in order to establish their professional credibility.

In this way, the anonymity of double blind refereeing is weakened if not totally destroyed. The smaller and more specialized the field, the easier it becomes to recognize the researcher, if not through the work itself, then certainly through the references contained in the article. Moreover, while the entry of commercial publishers into the arena of scholarly journal publishing did not in and of itself decrease the quality of what was being published, it placed the emphasis primarily upon quantity. It is not necessary to adhere to a rigid page budget for the year if it is possible to use an increase in the number of pages as a rationale for an increase in subscription price. The authors, editors, and referees who determine the content of scholarly journals are not expected to buy the journals. That is left to libraries, and their funding is separate from either the salary or research budget of the scholar. Moreover, libraries have been, up to now, more likely to absorb the rising costs of subscriptions without protest.

\section{WHY THE PROCESS WORKS FOR AUTHORS AND PUBLISHERS}

It is not my intent to suggest that authors and editors set about willfully to dilute the quality of research publications by increasing their quantity. It is possible that some unscrupulous publisher might be tempted to do this, but even that conjecture, if offered, could only be substantiated with difficulty. It is nevertheless clear that the publications resulting from the work of scholars have grown far more rapidly than the number of scholars themselves. People are writing more and more, but not necessarily because they have more to say.

Part of the explanation for the increase in publication has already been suggested. Neither authors, editors, nor referees have any financial responsibility for their decisions. While the content of scholarly journals is controlled by these 
groups, financial arrangements involve only the publisher and the organization that pays for the subscription-most frequently the library. Research shows that libraries have not found an effective way, in their institutional settings, to combat the pressures of increasing page counts and higher prices. ${ }^{6}$ These two factors may be related, as indeed some publishers' statistics.claim they are. However, for the billpaying librarian this does not matter, since librarians have never asked for either new or larger journals.

The smaller and more specialized the field, the easier it becomes to recognize the researcher, if not through the work itself, then certainly through the references contained in the article.

Originally, the refereeing process was intended to weed out and destroy proposed articles that did not warrant publication, either because the material was repetitive or because it added nothing new. However, a recent study indicated that at least some publishers are willing to publish material even though they know it is not original. ${ }^{7}$ They do it because of the pressure to fill their issues. However, they also do it to keep the article, particularly if written by a prominent or easily recognized author, from going to another journal, or perhaps contributing to the formation of a competing journal. Editors, therefore, feel some responsibility for including everything worth publishing in their discipline in their own journal because they don't want to encourage competition. As libraries increasingly face the prospect of canceling subscriptions (although budgeters tend to put off this decision as long as they possibly can by transferring funds from other internal priorities), the existence of a rival journal becomes of greater concern to the editor and publisher than the notion that some articles might not have warranted inclusion in the first place.

Why is all this happening? I suggest it is largely because the process of aca- demic evaluation, as practiced primarily in universities through the promotion and tenure procedures, has moved gradually from emphasis on the quality of a scholar's publications to concern with the quantity of the work. This has happened because the sheer volume and specificity of dossiers overwhelms the ability of those from other disciplines to understand and evaluate the content. With the readiness of publishers to start new journals (statistics indicate that carefully planned journals-at least carefully planned in identifying their intended audiencerarely fail), the process of refereeing in the journal literature does not succeed in keeping articles from being published, only in shifting them from journal A to journal B, or perhaps even to journal C. Journal C then becomes a crucial journal for the scholar whose article will appear there, and it becomes politically essential that the library purchase it as a validation of the research. The pressure to purchase $C$ becomes paradoxically greater than the pressure to purchase $A$, because $A$ will be purchased in any case. It has already been shown that, to a far greater extent than those involved would like to admit, libraries base cancellation decisions less on careful evaluation of need, and more significantly on what they can get away with canceling. ${ }^{8}$

\section{POSSIBLE SOLUTIONS AND CHANGES}

If there is a solution to this dilemma, it rests squarely with the academicians and scholars themselves, because it is ultimately they, and not librarians, who influence the actions of publishers. To a large extent librarians are seen only as purchasing agents with money, but with little say in what they are expected to buy. It is certainly also to the advantage of publishers, as for any vendor, to sell as much as possible at the highest possible price. Probably relatively few publishers act with such a cold singleminded approach to maximizing profits, but enough publishers do conduct business in such a way as to seriously damage the credibility of the larger publishing community. 
The solution to this dilemma must come from the recognition by scholars themselves that the present systemdispensing credit based on the quantity of publications by a given author-ultimately does not benefit the academic community. Attempts to measure quality will always be controversial and disputatious, and there is no certainty that any new system will please more people or produce fairer results. As long as humans are doing the judging there will be charges of bias, and letting computers do the judging antiseptically is something we are not prepared to do. For many individuals, their entire career futures are at stake.

Yet, despite all of these caveats, it should be recognized that the present system emphasizing quantity of publication must change. It encourages irresponsible and needless publication, which deluges the reader with huge amounts of material. Any operations researcher can tell us that it is easier to find what we need in a small collection than in a large one, provided that there is confidence that the smaller collection contains what is needed. In other words, redundant information is not just trivial waste. It can get in the way of finding the important and useful. This is the first reason for the necessity to change the current system of scholarly publication.

The second reason for changing the system is that given the finite and even decreasing support of library funding, the present approach of unlimited and unmonitored growth will bankrupt the academic information process. If the current system does not do this, it will at least have drained off so many resources from other needs and other priorities in the academic enterprise that the results will be equally catastrophic.

Research scholars are emerging who understand this issue and who recognize that the solution does not lie in finding more money (at best a dubious prospect) but in developing a new system of evaluating and crediting quality. Publishers do not necessarily see these scholars as friendly to the interests of the publishing community, and some have sought to intimidate these scholars into silence by dragging them through costly and time-consuming legal processes. However, librarians certainly should see these scholars as allies, and offer them all the help and encouragement that we can.

Nevertheless, it would probably be unrealistic to expect that either faculty or academic administrators will address this problem until and unless they absolutely have to do so. Actions such as those undertaken by the Faculty Senate at Southern Methodist University (SMU), which threatened to punish those publishers "guilty" of the greatest price increases by canceling these subscriptions regardless of qualitative and other political considerations, are still very much the exception rather than the rule, and as long as that situation continues, neither publishers nor academicians will feel any pressure to respond to the problem. In a perverse way, the willingness and remarkable ability of academic librarians to somehow find the money with which to meet continuing double-digit publisher price increases virtually assures that nothing will be done. We were even paid what was intended as a compliment in a recent article by Timothy King, a publisher who congratulated librarians on their resourcefulness in finding the necessary money for publications. 9

\section{STRATEGIES FOR LIBRARIANS}

What strategies and alternatives does this situation suggest for academic librarians? The first is the recognition that they cannot solve the problem because they lack the power and leverage. Publishers will not be motivated to take action as long as they are supported by a faculty who exercise much authority over but take little responsibility for the issues in academic publishing. Some publishers even patiently explain to librarians that the reason for the large rise in the price of subscriptions is because of an increase in submitted articles, or of the weakness of the U.S. dollar. In a free-market economy, those are their problems and not ours. It appears certain that university administrators will make a concerted effort not when librarians demand 
it, but when faculty demand it. Economists predict that prices are not likely to rise substantially in the stores where we shop because customers have no money. Manufacturers and vendors know that, and therefore know that they cannot increase prices. Librarians do not have any money either, but that makes very little difference to vendors. If vendors perceive librarians as purchasing agents rather than as customers, they have little motivation to respond to librarians' financial limitations. Therefore, the wellmeaning suggestion in the recent article by Bruce Kingma and Philip Eppard does not offer any solution. ${ }^{10}$ Kingma and Eppard correctly describe the difference between individual and library subscription prices, but their suggestion that the economic solution is to increase the cost of faculty photocopying services for library journals neglects the reality we know so well, that when photocopying is made unattractive, "direct appropriation of material" or mutilation grow in proportion. These authors maintain that whatever emerges into the scholarly publication process was worth publishing, or at least that the process cannot be changed. I would rather not be that pessimistic.

What, then, is the academic librarians' most effective strategy? We must state loudly and clearly that this disaster of ever-increasing periodical prices is neither our fault nor our problem, and that we have no solution we can implement. The available options include increased funding of the periodical budget from already scarce university funds, an accelerated process of cancellations, or an academic power structure commitment to do something about an absurd pricing growth that has connection neither to inflation nor to the number of scholars presumed to have something to report in the literature. Academic administrators will do something about this problem if they become convinced it is important enough to warrant concerted action, just as they finally felt impelled to deal with the escalating cost, confusion, and embarrassment of their athletic programs. Dare we suggest to them that this might be just as important?
Utilizing this sort of confrontational strategy is difficult and painful for librarians because our acceptance of the "moral imperative" (the premise that we must do everything with or without resources or it will all be our fault) appears to be an inbred value system that students already bring with them to library school without having to be taught. ${ }^{11}$ Where they acquire this virus I am not sure. Perhaps they learn this commitment to self-sacrifice from their mentors in the libraries in which so many students already work on a part-time basis.

One thing, however, seems certain to me. The unchecked bloodletting of the periodicals budget has perhaps gained librarians some additional funds, even if not nearly enough. But it has also removed the initiative for doing many of the other things we should be doing (automation, resource sharing, preservation, increased reference and bibliographic work, staff upgrading, and continuing education) because all the money is already allocated before we get to any of these priorities. To increase the irony, academic administrators truly believe that they have been financially supportive of their libraries, when in fact they have only really been supportive of a passthrough financial game in the continuation of a process sadly in need of evaluation and refinement. We need to stress that periodicals funding is not our only priority, and at this point we can't even allow it to be our primary priority.

\section{SOME FINAL THOUGHTS}

Articles such as this one are written at some risk of creating displeasure. The habit of executing the messenger who brings us bad tidings goes back a long way. There are academic library administrators who would prefer not to be reminded of how ineffective our strategies of the last twenty years have been. There may be other administrators who truly believe that progress is being made, and that there is light at the end of the tunnel. However, these optimists may confuse increased activity with progress. There has been an increasing number of meetings between publisher and librarian 
groups. Publishers may be inclined to talk as long as nothing changes while the talks go on. There has certainly been no modification in the price escalation of scholarly journals, and we can be certain there will be none as long as some publishers continue to suggest that this is our problem instead of theirs.

Meetings between librarians and groups of faculty members have also become more frequent, and some have been useful if only to explain the magnitude of the problem. However, while there have been some scattered reports of motions of concern expressed by various faculty bodies, and even vague threats of retribution, such scattered activities will not make an impression on the journal pricing process. What might make an impression would be a vote by the membership of an entire professional subject discipline to refuse to submit articles to particularly high-priced journals, or concrete action by a body of presidents representing major research institutions, such as the Ivy League or the Big Ten. There is no indication of such action on the horizon, and more talk provides a poor substitute.

There is also the hope that acceptance of concepts implementing what has been called the virtual library can offer some relief. Broadly based concepts of resource sharing are indeed very exciting, and it is important that they be pursued. However, they offer no relief for this particular problem unless institutions are prepared to divert funds from purchase of materials to a resource-sharing mecha- nism. Such action, if seriously contemplated, would probably require modification of present copyright legislation, particularly in light of recent narrow court interpretations of Section 107 of the U.S. Copyright Act of 1976. Such modification would not be impossible, but it is not likely to occur in the near future. Faculty and administrators presently understand the virtual library to be a means of sharing resources after librarians have already spent every last available dollar on purchase, and subsequently found that the resources are inadequate. Under such constraints virtual library concepts are still worthwhile, but they require much more additional spending. If the need for even more funding has been communicated to any university administrators, they appear to pay it little heed. And yet, somebody has to explain to them that libraries cannot continue to spend every last cent on material purchase and then also implement virtual libraries. Funds must be diverted from purchase, or new funds must be added. Faculty don't like the first option and university administrators don't like the second.

Librarians have been entangled in this web for the last twenty years, and extricating ourselves is a difficult task. The situation puts me in mind of advice from my college varsity tennis coach, many years ago. "Never change a winning game, but always change a losing game. You risk nothing when you do." How many sets do we have to lose before we reassess our strategies?

\section{REFERENCES}

1. Derek J. de Solla Price, Little Science, Big Science (New York: Columbia Univ. Pr., 1963).

2. Allen Kent, et al., Use of Library Materials: The University of Pittsburgh Study (New York: Dekker, 1979).

3. Bernard M. Fry and Herbert S. White, Publishers and Libraries: A Study of Scholarly and Research Journals. (Lexington, Mass.: Heath, 1976).

4. Herbert S. White, "Publishers, Libraries, and Costs of Journal Subscriptions in Times of Funding Retrenchment," Library Quarterly 46 (Oct. 1976): 359-77.

5. - "Scholarly Publishers and Libraries: A Strained Marriage," Scholarly Publishing vol.19, no.3(Apr. 1988): 125-29.

6. , "Librarians, Journal Publishers and Scholarly Information: Whose Leaky Boat Is Sinking?" LOGOS vol.1, no.4(1990): 18-23.

7. Judith Serebnick and Stephen P. Harter, "Ethical Practices in Journal Publishing: A Study of Library and Information Science Periodicals," Library Quarterly 60 (Apr. 1990): 91-119. 
8. Herbert S. White, "Factors in the Decision by Individuals and Libraries to Place or Cancel Subscriptions to Scholarly and Research Journals," Library Quarterly 50 (July 1980): 287-309.

9. Timothy B. King, "Journal Publishers, Librarians, and Scholarly Information: Contemplating a Future Scenario," LOGOS vol.1, no.4 (1990): 24-29.

10. Bruce R. Kingma and Philip B. Eppard, "Journal Price Escalation and the Market for Information: The Librarians' Solution," College \& Research Libraries vol.53, no.6 (Nov. 1992): 523-35.

11. White, Herbert S. "Playing Shell Games without Any Peas," Library Journal vol.116, no.12 (July 1991): 63-64.

\section{Let Your Researchers Be Partners in BIOSIS Searching.}

With BIOSIS' Biological Abstracts ${ }^{\circ}$ on $C D$ and Biological Abstracts $/ \boldsymbol{R R M}^{\circ}$ on $\mathbf{C D}$, your researchers don't have to be expert searchers to access the world's life science literature. Here's why:

\section{Comprehensive Coverage}

In 1993, Biological Abstracts on CD and Biological Abstracts/RRM on CD will contain 540,000 references to original research articles, meetings, books, reviews and more. No other source matches BIOSIS' coverage.

\section{Easy-to-use}

BIOSIS' compact discs employ SilverPlatter" Information, Inc.'s user-friendly software, so your researchers can pinpoint relevant life science information - quickly and easily!

\section{Economical}

With up-front, flat-fee pricing, researchers can browse through citations and abstracts - without incuming additional charges associated with online services.

\section{Call for a 30-Day Free Trlal Disc!}

1-800-523-4806 (USA and Canada); (215) 587-4847 (Worldwide). Or write to the BIOSIS Marketing and Sales Department CRL793CD, 2100 Arch Street, Philadelphia, PA 19103-1399 USA. Fax: (215) 587-2016. Intemet: biosis@al.relay.upenn.edu

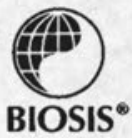




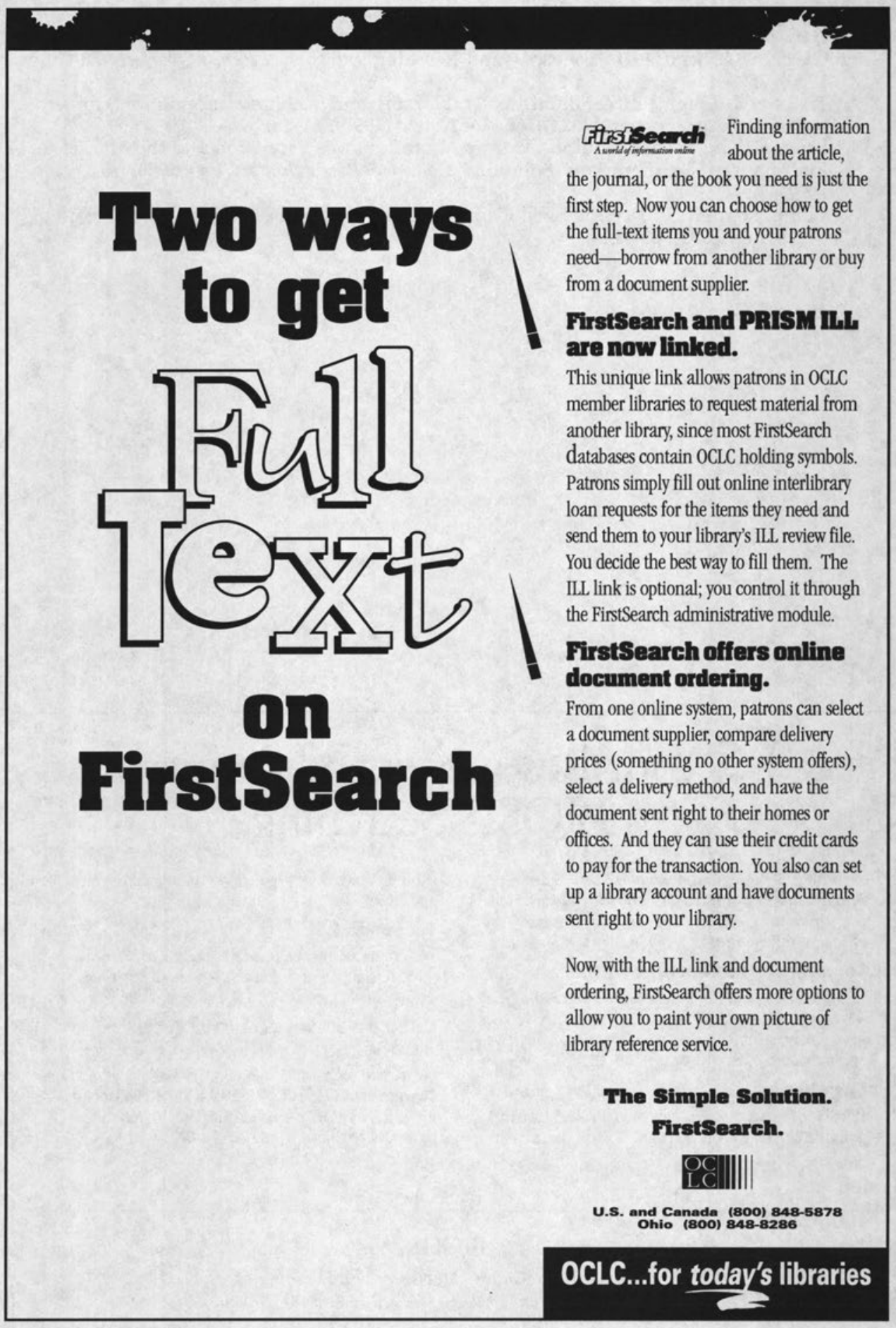

